\title{
Increased in vivo release of neuropeptide $S$ in the amygdala of freely moving rats after local depolarisation and emotional stress
}

\author{
Karl Ebner • Alesja Rjabokon • Hans-Christian Pape • \\ Nicolas Singewald
}

Received: 30 June 2011 / Accepted: 8 August 2011/Published online: 23 August 2011

(c) The Author(s) 2011. This article is published with open access at Springerlink.com

\begin{abstract}
Intracerebral microdialysis in conjunction with a highly sensitive radioimmunoassay was used to study the in vivo release of neuropeptide S (NPS) within the amygdala of freely moving rats. NPS was consistently detected in basolateral amygdala dialysates and the release considerably enhanced in response to local depolarisation as well as exposure to forced swim stress. Thus, our data demonstrate for the first time emotional stress-induced release of NPS in the amygdala supporting a functional role of endogenous NPS in stress/anxiety-related phenomena.
\end{abstract}

Keywords Neuropeptide S antibody · Anxiety .

Depression · Stress-related disorders · Microdialysis ·

Radioimmunoassay

\section{Introduction}

The recently discovered neuropeptide S (NPS) and its cognate receptor (NPSR) have been found to be involved in various behavioral functions including stress and fear/anxiety reactions (for review see Okamura and Reinscheid 2007; Pape et al. 2010). Considerable evidence suggests that the amygdala may be a critical site of action for NPS mediating stress and anxiety mechanisms. This idea was initially based

K. Ebner $(\varangle) \cdot$ A. Rjabokon · N. Singewald

Department of Pharmacology and Toxicology,

Institute of Pharmacy, Center for Molecular Biosciences

Innsbruck (CMBI), Leopold-Franzens-University of Innsbruck,

Peter Mayr-Str.1, 6020 Innsbruck, Austria

e-mail: karl.ebner@uibk.ac.at

H.-C. Pape

Institute of Physiology I, Westfälische-Wilhelms-University,

Münster, Germany on anatomical findings demonstrating a high density of NPSR mRNA expression in the amygdala of rats and mice (Xu et al. 2004, 2007; Jüngling et al. 2008; Leonard and Ring 2011). Within the murine amygdala NPSR were found in several subdivisions including the lateral (LA) and basal (BA) amygdala (Jüngling et al. 2008; Clark et al. 2011). Furthermore, the two brain stem sites containing NPS-synthesizing neurons give rise to NPS-immunopositive fibers, which overlap well with NPSR mRNA expression (Clark et al. 2011). However, the exact distribution of NPS fibers and terminals within the amygdala of rodents has not been studied adequately so far. The high abundance of binding sites within the amygdala of rats and mice suggests that the NPS system may play a crucial role in multiple amygdala functions such as controlling emotional processes. Indeed, behavioral studies in mice have shown that fear and anxietyrelated behaviors are reduced after intraamygdaloid administration of NPS (Jüngling et al. 2008; Fendt et al. 2010). Conversely, the injection of a selective NPSR antagonist into the amygdala exerts functionally opposing responses, an increase of anxiety-related behavior, suggesting an involvement of endogenous NPS in behavioral regulation (Jüngling et al. 2008). Thus, these studies support the idea that NPS acts as a neurotransmitter/neuromodulator in the amygdala to mediate emotional processes including stress and anxiety mechanisms. Forced swim stress in mice was indeed found to increase c-fos activity in NPS-synthesizing neurons in the brain stem (Liu et al. 2011), implying that the NPS system may be stimulated upon stress exposure. However, direct evidence for such a role from in vivo sampling measurements such as microdialysis that enables monitoring neurotransmitter/neuromodulator release within distinct brain areas of freely behaving animals is still missing. Measurements of the release of NPS in the amygdala in response to stressful and aversive stimuli would present 
intriguing prospects for determining neurotransmitter/neuromodulator function of NPS within this limbic area under physiologically relevant conditions.

In the present study, we describe the use of intracerebral microdialysis in combination with a sensitive radioimmunoassay to monitor the neuronal efflux of NPS in the rat amygdala under basal and depolarizing conditions. Furthermore, we investigated whether a stressful and anxietyprovoking situation such as exposure to forced swimming would also be sufficient to trigger NPS release in the amygdala.

\section{Materials and methods}

\section{Animals}

Experiments were carried out on adult male SpragueDawley rats $(300-350 \mathrm{~g})$. Prior to use, the animals were housed in groups of 4-6 under controlled laboratory conditions $(12: 12 \mathrm{~h}$ light/dark cycle with lights on at 7:00 A.M., $21 \pm 1{ }^{\circ} \mathrm{C}, 60 \%$ humidity, pelleted food and water ad libitum) for at least one week after delivery from the supplier. All experiments were approved by the local Ethics Committee on Animal Care and Use of the Austrian governmental body (Bundesministerium für Wissenschaft and Verkehr, Kommission für Tierversuchsangelegenheiten, Ref No: BMWF-66.008/0014-II/10b/2010).

\section{Surgery}

Rats were anesthetized by intraperitonal injections of sodium pentobarbital $(40 \mathrm{mg} / \mathrm{kg})$ and ketamine $(50 \mathrm{mg} / \mathrm{kg})$ and a microdialysis probe was stereotaxically implanted according to the brain atlas of Paxinos and Watson (1998). The probe consisting of an $18-\mathrm{kDa}$ dialysis membrane (Hemophan, Membrana, Wuppertal, Germany) with an active surface length of $1 \mathrm{~mm}$ was positioned with its U-shaped tip reaching the right basal/lateral amygdala (BA/LA) (Fig. 1; implantation coordinates: $2.8 \mathrm{~mm}$ caudal to bregma, $2.5 \mathrm{~mm}$ lateral to the midline, $9.2 \mathrm{~mm}$ below the surface of the skull with an angle of $15^{\circ}$ ). The probe was fixed to the skull with two jeweler's screws and dental cement. The two endings of the probe were attached to $5-\mathrm{cm}$ long pieces of polyethylene tubing for connection with the infusion pump. Postoperatively, rats were treated with Buprenorphine $(0.1 \mathrm{mg} / \mathrm{kg}$ body weight, s.c. every $8 \mathrm{~h}$ ) and housed individually in transparent plexiglas cages. They were handled for $3 \mathrm{~min}$ twice daily to familiarize them with the experimental procedure and to minimize nonspecific stress responses during the experiments. At least $24 \mathrm{~h}$ before the experiment, animals were kept in the experimental room and allowed to habituate.
Microdialysis procedure

Two days after surgery, the implanted microdialysis probe was connected to a syringe mounted onto a microinfusion pump and superfused with artificial cerebrospinal fluid (aCSF: $140 \mathrm{mM} \mathrm{NaCl}, 3.0 \mathrm{mM} \mathrm{KCl}, 1.25 \mathrm{mM} \mathrm{CaCl}_{2}$, $1.0 \mathrm{mM} \mathrm{MgCl}_{2}, 1.2 \mathrm{mM} \mathrm{Na}_{2} \mathrm{HPO}_{4}, 0.3 \mathrm{mM} \mathrm{NaH}_{2} \mathrm{PO}_{4}$ and $3.0 \mathrm{mM}$ glucose, $\mathrm{pH}$ 7.2) at a flow rate of $4 \mu \mathrm{l} / \mathrm{min}$. To minimize the binding of NPS to the plastic surfaces and to reduce peptidase activity, bovine serum albumin $(0.2 \%)$ and bacitracin $(0.03 \%)$ were included in the perfusion medium. Microdialysis probes were initially dialyzed for $120 \mathrm{~min}$ to establish an equilibration between the inside and outside of the microdialysis membrane. During this equilibration period, sample collection was simulated every $30 \mathrm{~min}$ to adapt animals to the microdialysis procedure but dialysates were discarded. Thereafter, various consecutive 30-min dialysates were collected directly into Eppendorf vials, which were stored at $-80^{\circ} \mathrm{C}$ until assay.

\section{Experimental protocol}

In the first series of experiments, perfusion with high potassium-containing aCSF was used to elicit local depolarization. Three basal 30-min samples were collected after a 120-min equilibration period. Subsequently, probes were dialyzed with aCSF containing $100 \mathrm{mM} \mathrm{KCl}$ for a further 30-min period. During these experiments, rats remained in their home cages.

In the second series of experiments, we investigated the effects of stress exposure on NPS release. Therefore, rats were dialyzed initially with aCSF for $120 \mathrm{~min}$ to collect four baseline samples in their home cages. At the beginning of the fifth dialysis interval, animals were transferred from their home cage to a swim tank (square plastic tank, $35 \times 35 \times 42 \mathrm{~cm}$; filled with water at $20^{\circ} \mathrm{C}$ up to a height of $30 \mathrm{~cm}$ ) for $10 \mathrm{~min}$ with ongoing microdialysis. Thereafter, they were gently dried using a towel and returned to their home cage. After stress exposure, dialysis was continued for further $140 \mathrm{~min}$ when rats were undisturbed within their home cages. At the end of each experiment, animals were disconnected from the microdialysis lines and blank samples (e.g. aCSF and aCSF containing $100 \mathrm{mM} \mathrm{KCl}$ ) were collected that were run as blank controls in the same analysis as the sample microdialysates.

\section{Histology}

At the end of the experiment, the animals were killed by an overdose of pentobarbital $(600 \mathrm{mg} / \mathrm{kg})$ and their brains removed. For histological verification of the localization of the microdialysis probes, brains were sectioned and $40 \mu \mathrm{m}$ coronal sections were stained with cresyl violet. 
Fig. 1 Probe placements in the amygdala. a A representative photomicrograph of a cresylstained coronal section showing the localization of the tip of the membrane of a microdialysis probe (arrowhead) within the BA/LA. b Schematic drawings of the localization of the microdialysis membranes (bold black lines) used in the present study within and outside of the BA/LA. $B A$ basal amygdala, $L A$ lateral amygdala. Illustrations modified from Paxinos and Watson (1998)

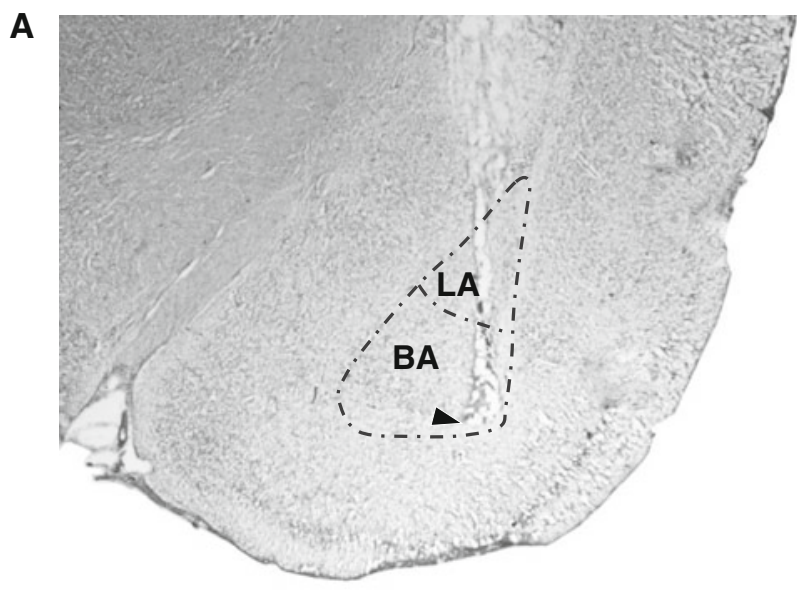

B
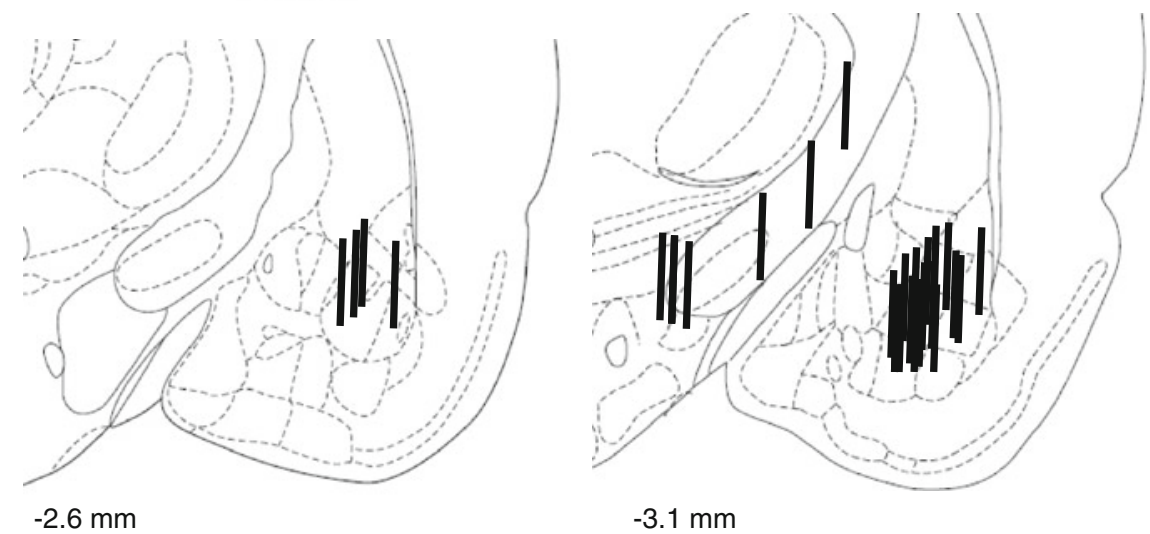

The locations of microdialysis probes within BA/LA (Fig. 1) were determined on the basis of previous definitions of a brain atlas (Paxinos and Watson 1998). Judgment of successful implantation of probes into the amygdala was made before analyzing data from release experiments.

\section{Quantification of NPS in microdialysates}

The concentration of NPS was measured in microdialysates by a highly sensitive and selective radioimmunoassay. As the sensitivity of the antibody is a critical component of the radioimmunological measurement, we performed various standard curves using different commercially available polyclonal rabbit antisera to rat NPS (Table 1). The used assay system was further optimized by performing antibody dilution curves which involves the incubation of a fixed amount of tracer with different concentrations of antibody to determine the amount of antibody optimal for use in a microdialysate-relevant standard curve. In each assay, known amounts of synthetic NPS (H-6164, Bachem) were serially diluted $(0.5,1,2,4$, $8,16,32,64,128 \mathrm{pg} / 100 \mu \mathrm{l}$ RIA buffer) and preincubated with $100 \mu \mathrm{l}$ of 1:50 diluted NPS-antiserum for $48 \mathrm{~h}$ at $4^{\circ} \mathrm{C}$ before the tracer ligand (Bachem) was added. We found that the antibody T-4808 (Bachem) has sufficient sensitivity to be used for setting up a standard curve in the desired concentration range (Table 1). This antibody has been shown to display no cross-reactivity with other structurally related peptides such as human NPS that has only minor differences in amino acid sequence (http://www.bachem.com). After addition of $100 \mu \mathrm{l}$ radioiodinated NPS (approximately $8,000 \mathrm{cpm}$ in $100 \mu \mathrm{l}$ ), all samples were further incubated for $48 \mathrm{~h}$ at $4^{\circ} \mathrm{C}$. Antibodybound radioligand was separated from unbound radioligand by addition of charcoal $(1 \mathrm{ml})$ and centrifugation $\left(2,056 \times g\right.$ for $10 \mathrm{~min}$ at $\left.4^{\circ} \mathrm{C}\right)$. The supernatant was decanted, and the bound radioactivity was counted in a gamma counter. The detection limit of the assay was about $0.1 \mathrm{pg}$ per sample $(=1 \mathrm{pg} / \mathrm{ml})$.

\section{Statistics}

Statistical analysis was performed using a computer software package (GB-Stat 6.0, Dynamic Microsystems, Silver Springs, USA). Data were expressed as raw data and submitted to a one-way (high $\mathrm{KCl}$ experiments) or two-way ANOVA with repeated measures (group $\mathrm{x}$ time, forced swim experiments) followed by appropriate post hoc analysis. Thereby, NPS levels during and after high potassium or forced swimming were compared with each single point 
Table 1 Comparison of different commercially available antibodies used in this study

\begin{tabular}{llllll}
\hline Code & Source & $\mathrm{B} 0(\%)$ & $\mathrm{ED}_{80}(\mathrm{pg} /$ tube $)$ & $\mathrm{ED}_{50}(\mathrm{pg} / \mathrm{tube})$ & $\mathrm{ED} 20(\mathrm{pg} /$ tube $)$ \\
\hline ab-1852 & Abcam & 11.7 & n.d. & n.d. & n.d. \\
S-2201 & Bachem & 34.9 & 2.9 & 10.2 & 36.1 \\
T-4808 & Bachem & 28.3 & 1.6 & 8.3 & 42.2 \\
\hline
\end{tabular}

BO maximal binding, $n . d$. not detectable because ab-1852 failed to displace tracer at concentrations used for the standard curve $\mathrm{ED}_{20} 5080: 80,50$ and $20 \%$ displacement of tracer

of the baseline. Data are presented as mean \pm SEM. Significance was accepted if $P<0.05$.

\section{Results}

Effect of high $\mathrm{KCl}$ on the release of NPS within the amygdala

The NPS content of dialysates collected in the BA/LA under basal conditions was consistently above the detection limit of the radioimmunoassay, reaching an average concentration of $1.7 \pm 0.5 \mathrm{pg}$ /dialysate $(N=9)$. Although histological analysis of probe placement revealed that in all 11 animals of this experiment probes were placed within the BA/LA, two animals had to be excluded from the study because basal levels were under the detection limit of the assay. As illustrated in Fig. 2a, administration of $100 \mathrm{mM} \mathrm{KCl}$ in the perfusion medium for $30 \mathrm{~min}$ caused an 500\% increase in extracellular NPS concentration yielding dialysate levels of $8.5 \pm 2.0 \mathrm{pg} /$ dialysate (one-way ANOVA $F_{3,24}=11.35, P<0.0001$ ). During perfusion with high $\mathrm{KCl}$ we observed no behavioral abnormalities. Moreover, an interference of $\mathrm{KCl}$ solution with RIA analysis can be excluded because no detectable
NPS levels were measured in the analysis of blank samples (see above).

Effects of forced swimming on the release of NPS within the amygdala

Histological analysis of probe placement revealed that 11 out of 17 probes were placed within the BA/LA whereas 6 were localized outside the amygdala, 3 within the internal capsule and 3 within the lateral hypothalamus. The basal level of NPS within the BA/LA before stress exposure was $2.5 \pm 0.3 \mathrm{pg}$ /dialysate $(N=11)$. For comparison, the basal NPS levels in the internal capsule and lateral hypothalamus were $0.7 \pm 0.2$ and $2.3 \pm 0.2$, respectively. For statistical comparison all outsiders were summarized in one group. As shown in Fig. 2b, swim stress caused a significant increase in the NPS content of microdialysates collected from the BA/ LA amounting to $200 \%$ of the basal release. Statistical analysis by two-way ANOVA revealed a significant difference in NPS release patterns between animals with correct probe placement within the amygdala and animals where probe placements were localized outside the amygdala (group: $F_{1,15}=11.97, P=0.0035$; time: $F_{8,120}=2.43$, $P=0.018$; interaction between main factors: $F_{8,120}=3.59$, $P=0.0009)$. Post hoc analysis revealed a significant

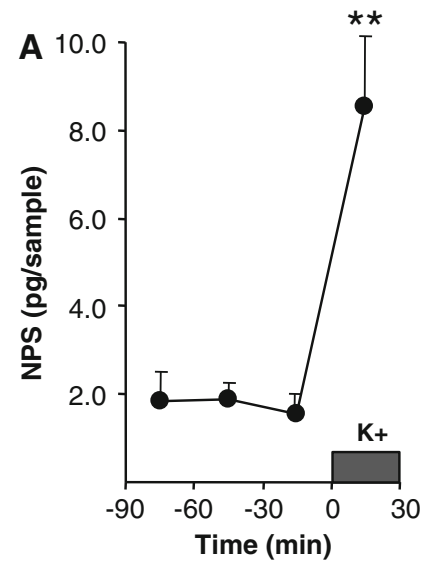

Fig. 2 NPS release within the amygdala. a Effect of high potassium and $\mathbf{b}$ forced swimming on the content of NPS in 30-min microdialysates sampled consecutively within (solid circles) or outside (open circles) the amygdala of freely moving rats. Animals were perfused with aCSF containing $100 \mathrm{mM} \mathrm{KCl}$ (black bar) or exposed to forced

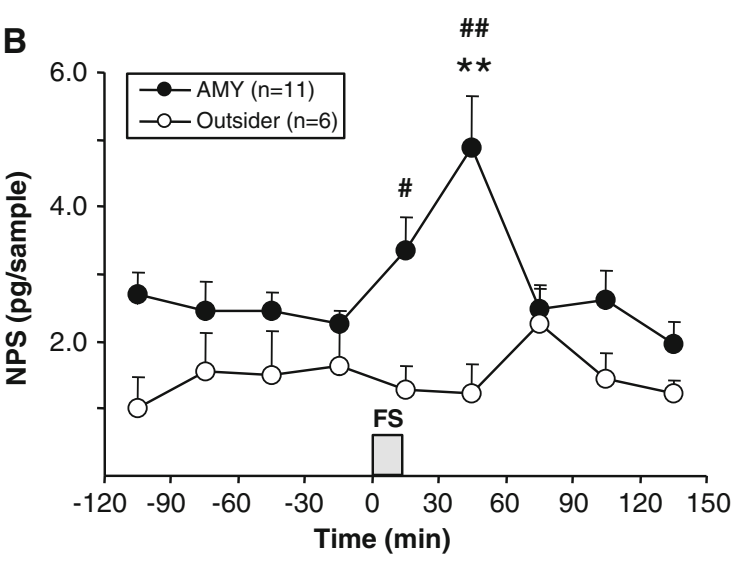

swimming (FS; gray-shaded bar) for 10 min during the fourth or fifth dialysis interval, respectively. Data expressed as mean + SEM. ${ }^{* *} P<0.01$ versus respective baseline; ${ }^{\#} P<0.05,{ }^{\# \#} P<0.01$ versus respective value in the 'outsider' group (Newman-Keuls post hoc test) 
increase of NPS efflux during and after stress exposure only in animals with correct probe placement within the amygdala. Notably, the stress-evoked NPS release reached a peak level $60 \mathrm{~min}$ after onset of the stressor and returned to prestress values about 90 min after stress exposure. In contrast, NPS-content in microdialysates sampled outside the amygdala either in the internal capsule or lateral hypothalamus did not increase during stress exposure and remained unchanged throughout the entire dialysis period (Fig. 2b).

\section{Discussion}

The results of the present study demonstrate for the first time that NPS release within the amygdala can be monitored in conscious rats both under stimulated and basal/resting conditions by using microdialysis in conjunction with a highly sensitive radioimmunoassay. NPS release in the BA/LA was considerably enhanced in response to local high potassiuminduced depolarisation as well as stressfull situation by exposure of rats to forced swimming. Notably, the latter effect was found only in animals where microdialysis probes were localized within the amygdala region and not in surrounding areas such as internal capsule and lateral hypothalamus. Thus, a contamination of "functional-relevant" NPS from these surrounding areas can be excluded, although detectable basal NPS levels were found in both areas.

The investigation of the in vivo efflux of neuropeptides such as NPS by microdialysis is particularly challenging and is hampered by the low concentrations of these molecules in the extracellular fluid (ranging from sub pico- to femtomolar levels), the low recovery of peptides via microdialysis sampling ( $<10 \%$ typically) and the small volume of dialysates generated. Thus, it needs extremely sensitive analytical procedures to determine NPS in microdialysates. In our study we used a novel, highly sensitive radioimmunoassay developed from a protocol we have used for the detection of other neuropeptides such as substance $\mathrm{P}$ (Ebner et al. 2004). Besides the need of a highly sensitive analytical technique, the optimization of microdiaysis recovery was just as important as enhancing method sensitivity to quantify NPS in microdialysates. However, the recovery for any analyte in microdialysis sampling is a complex process that may be influenced by several parameters, including flow rate, probe geometry as well as membrane properties (e.g. length, material). Concerning probe geometry we used a U-shaped cannula design because of its improved recovery properties compared with the concentric one (Horn and Engelmann 2001). To identify the membrane type with the optimal recovery for NPS, we compared three different membranes (cuprophane, hemophane and polyethersulfone) for their efficiency in recovering NPS. Although recovery differences between membranes were minimal, the most efficient membrane types were polyethersulfone and hemophane. However, due to the brittle and fragile properties of the polyethersulfone fiber, making it difficult to use with a U-shaped cannula design, we used hemophane probes for our in vivo experiments. The reliable measurement of NPS in microdialysates was likely improved by the addition of BSA to the perfusion medium which has been shown to be efficient in minimizing nonspecific adsorption of sticky neuropeptides to glass and plastic surfaces (Kendrick 1990). Moreover, a further precaution against a loss of the already low peptide levels in microdialysis samples was the addition of the peptidase inhibitor bacitracin to the perfusion fluid to minimize enzymatic breakdown.

In summary, the present results evaluated the possibility of applying microdialysis for monitoring NPS release in distinct brain areas of freely moving rats. Thus, we could demonstrate for the first time that this method in combination with highly sensitive analytical procedures is a suitable tool to investigate the characteristics and dynamic changes of centrally released NPS. Our data also support the notion that NPS acts as part of neurotransmitter/neuromodulator systems that are stimulated in response to a stressor. In line with this conclusion is the previous finding that forced swim stress increases c-fos activity in NPSpositive neurons in the brain stem (Liu et al. 2011). Since the amygdala is considered a critical site for transforming stressful events into anxiety (Roozendaal et al. 2009), our data also suggest that stress-induced NPS release within the amygdala can modulate stress and anxiety responsiveness. Along these lines, it was recently reported that a functional polymorphism in the NPSR gene changes amygdala responsiveness to aversive stimuli potentially contributing to anxiety traits (Dannlowski et al. 2011). Considering this evidence of a possible involvement of NPS in the etiology of anxiety disorders in humans (see also Donner et al. 2010; Domschke et al. 2011), it seems that interfering with this NPS-mediated pathway may have therapeutic relevance in psychopathologies including anxiety disorders.

Acknowledgments Supported by the Austrian Research Fund FWF (SFB F4410, to NS) and a grant from the Deutsche Forschungsgemeinschaft (SFB-TRR58, TP A03, to HCP) and the Max-PlanckAward (to HCP).

Open Access This article is distributed under the terms of the Creative Commons Attribution Noncommercial License which permits any noncommercial use, distribution, and reproduction in any medium, provided the original author(s) and source are credited.

\section{References}

Clark SD, Duangdao DM, Schulz S, Zhang L, Liu X, Xu YL, Reinscheid RK (2011) Anatomical characterization of the 
neuropeptide $\mathrm{S}$ system in the mouse brain by in situ hybridization and immunohistochemistry. J Comp Neurol 519:1867-1893

Dannlowski U, Kugel H, Franke F, Stuhrmann A, Hohoff C, Zwanzger P, Lenzen T, Grotegerd D, Suslow T, Arolt V, Heindel W, Domschke K (2011) Neuropeptide-S (NPS) receptor genotype modulates basolateral amygdala responsiveness to aversive stimuli. Neuropsychopharmacology 36:1879-1885

Domschke K, Reif A, Weber H, Richter J, Hohoff C, Ohrmann P, Pedersen A, Bauer J, Suslow T, Kugel H, Heindel W, Baumann C, Klauke B, Jacob C, Maier W, Fritze J, Bandelow B, Krakowitzky $\mathrm{P}$, Rothermundt $\mathrm{M}$, Erhardt A, Binder EB, Holsboer F, Gerlach AL, Kircher T, Lang T, Alpers GW, Ströhle A, Fehm L, Gloster AT, Wittchen HU, Arolt V, Pauli P, Hamm A, Deckert J (2011) Neuropeptide S receptor geneconverging evidence for a role in panic disorder. Mol Psychiatry (in press)

Donner J, Haapakoski R, Ezer S, Melén E, Pirkola S, Gratacòs M, Zucchelli M, Anedda F, Johansson LE, Söderhäll C, OrsmarkPietras C, Suvisaari J, Martín-Santos R, Torrens M, Silander K, Terwilliger JD, Wickman M, Pershagen G, Lönnqvist J, Peltonen L, Estivill X, D’Amato M, Kere J, Alenius H, Hovatta I (2010) Assessment of the neuropeptide $\mathrm{S}$ system in anxiety disorders. Biol Psychiatry 68:474-483

Ebner K, Rupniak NM, Saria A, Singewald N (2004) Substance P in the medial amygdala: emotional stress-sensitive release and modulation of anxiety-related behavior in rats. Proc Natl Acad Sci USA 101:4280-4285

Fendt M, Imobersteg S, Burki H, McAllister KH, Sailer AW (2010) Intra-amygdala injections of neuropeptide $S$ block fear-potentiated startle. Neurosci Lett 474:154-157

Horn TF, Engelmann M (2001) In vivo microdialysis for nonapeptides in rat brain - a practical guide. Methods 23:41-53
Jüngling K, Seidenbecher T, Sosulina L, Lesting J, Sangha S, Clark SD, Okamura N, Duangdao DM, Xu YL, Reinscheid RK, Pape HC (2008) Neuropeptide S-mediated control of fear expression and extinction: role of intercalated GABAergic neurons in the amygdala. Neuron 59:298-310

Kendrick KM (1990) Microdialysis measurement of in vivo neuropeptide release. J Neurosci Methods 34:35-46

Leonard SK, Ring RH (2011) Immunohistochemical localization of the neuropeptide $S$ receptor in the rat central nervous system. Neuroscience 172:153-163

Liu X, Zeng J, Zhou A, Theodorsson E, Fahrenkrug J, Reinscheid RK (2011) Molecular fingerprint of neuropeptide S-producing neurons in the mouse brain. J Comp Neurol 519:1847-1866

Okamura N, Reinscheid RK (2007) Neuropeptide S: a novel modulator of stress and arousal. Stress 10:221-226

Pape HC, Jungling K, Seidenbecher T, Lesting J, Reinscheid RK (2010) Neuropeptide S: a transmitter system in the brain regulating fear and anxiety. Neuropharmacology 58:29-34

Paxinos G, Watson C (1998) The rat brain in stereotaxic coordinates. Academic Press

Roozendaal B, McEwen BS, Chattarji S (2009) Stress, memory and the amygdala. Nat Rev Neurosci 10:423-433

Xu YL, Reinscheid RK, Huitron-Resendiz S, Clark SD, Wang Z, Lin SH, Brucher FA, Zeng J, Ly NK, Henriksen SJ, de Lecea L, Civelli O (2004) Neuropeptide S: a neuropeptide promoting arousal and anxiolytic-like effects. Neuron 43:487-497

Xu YL, Gall CM, Jackson VR, Civelli O, Reinscheid RK (2007) Distribution of neuropeptide $S$ receptor mRNA and neurochemical characteristics of neuropeptide S-expressing neurons in the rat brain. J Comp Neurol 500:84-102 